Kochen des Leinöls zunächst „Leinölsäureanhydrid" entsteht, Recht hat, so würde wohl auch dies Wasserbildung zur Folge haben. Indessensprichtschon der Geruch beim Firnissieden dafür, da $B$ etwa frei werdendes Glycerin in flüchtige Zersetzungsprodukte übergeht. D. Ref.) - Von hohem Interesse für die Firnischemie dürfte eine Untersuchung von C. O. Weber ${ }^{133}$ ) über die Chemie des Kautschuks sein. Es zeigte sich, daß die Kügelchen, aus welchen die Kautschukmilch sich zusammensetzt,, aus einer dünnen Eiweißhülle und einem öligen Inhalt bestehen. ( $\mathrm{Da} \beta$ a u ch bei den fetten Ölen, wie sie in der Natur vorkommen, die einzelnen Fetttröpfchen von Eiweißhüllen umgeben seien, hat Bock ${ }^{134}$ ) schon vor mehr als 30 Jahren behauptet. D. Ref.) Beim Ausschütteln der Kautschukmilch mit Äther gehen die Kügelchen vollständig in Lösung, es hinterbleibt eine klare, wässerige Flüssigkeit. Der Äther hinterläßt beim Verdunsten eine dicke ölige Flüssigkeit, welche, besonders unter dem Einfluß des Lichtes, rasch zäh und nach zwei Stunden völlig fest wird. Der feste Körper zeigt nunmehr alle Eigenschaften des Kautschuks und ist in $\ddot{A}$ ther vollkommen unlöslich. Den Vorgang des Festwerdens erklärt Weber, ohne Zweifel mit Recht, durch Polymerisation. (Schon im Jahre $1892^{135}$ ) habe ich darauf hingewiesen, dab die beim Kochen des Leinöls ohne Luftzutritt eintretende Verdickung in der Hauptsache auf Polymerisation beruht. Derartig verdicktes Leinöl (Dicköl, Standöl) wurde damals in verschiedenen Stadien des Prozesses untersucht, die betreffenden Präparate wurden aber irrtümlicherweise als "Leinölfirnisse" bezeichnet. Daß beim Trocknen des Leinöls, und der Leinölfirnisse ein Oxydationsprozeß die Hauptrolle spielt, ist noch nie bestritten worden, aber auch dieser dürte von Polymerisationsvorgängen begleitet sein.

D. Ref.) -(Fortsetzung folgt.)

\section{Die in der Färberei noch verwendeten natürlichen Farbstoffe und ihre Wert= bestimmung.}

Von v. Cochenuausen, Chemnitz. (Eingeg. d. 18.38. 1904.)

Von den zahlreichen, dem Tier- und Pflanzenreiche entstammendenFarbmaterialien,

\footnotetext{
133) Berl. Berichte 1903, 3108.

134) Dingl. Journ. 1872, 560 .

135) Diese Z. 1892, 171.
}

welche noch im Anfange des vorigen Jahrhunderts die Lehr- und Handbiicher des Färbers und Druckers schmückten, ist eins nach dem anderen verschwunden, und es sind nur noch wenige übrig geblieben, welche in den neueren Werken der Erwähnung wert gehalten werden, aber sich nur einer kurzen und oft sehr wenig verständlichen oder unrichtigen Besprechung erfreuen. Jetzt, wo wiederum einer der ältesten Farbstoffe, der Pflanzenindigo, dem Kunstindigo weichen mub, ist es vielleicht Zeit, sich noch einmal der noch existierenden alten Farbstoffe zu erinnern. Überdies bietet das Studium dieser alten Materialien und besonders der Art ihrer Anwendung so viel Interessantes und Lehrreiches, daß selbst dann, wenn sie einmal vollständig verdrängt sind, und keins von ihnen mehr verwendet wird, der Färbereichemiker noch lange Zeit in Dankbarkeit sich ihrer erinnern und seine Studien mit ihnen beginnen wird, da sie vorzüglich geeignet sind, über die verschiedenen chemischen Prozesse, welche bei der Färberei in Frage kommen können, Aufklärung zu geben.

Es ist nicht beabsichtigt, die chemische Natur dieser alten Farbmaterialien abermals einer eingehenden Besprechung zu unterziehen, was überdies in dem Werke von $R^{1} e^{1}$ ) in sehr eingehender Weise erst vor kurzem geschehen ist, sondern es sollen nur das Prinzip und die Art ihrer Anwendung, die Gründe, warum sie noch verwendet werden, die Waren, zu deren Färbung sie noch dienen, und die einfachsten Methoden ihrer Wertbestimmung in einer Reihenfolge, welche zugleich den Grad ihrer Wichtigkeit ausdrückt, angegeben werden.

Die gerbsäurehaltigen Pflanzenteile gehören zu den ältesten Farbmaterialien. Der geringere Verbrauch, welcher durch den Ersatz des sogenannten Ordinärschwarz aus Gerbsäure und Eisensalzen durch das Blauholzchromschwarz für Wolle und das Anilinschwarz für Baumwolle entstanden war, ist reichlich aufgehoben worden durch den weit größeren Bedarf, welcher sich für ihre Verwendung als Beize und Befestigungsmittel der Beizen für die künstlichen Farbstoffe notwendig gemacht hat. In früheren Jahren wurden nur die Abkochungen der gerbsäurehaltigen Pflanzenteile verwendet, jetzt verwendet man fast nur die technisch dargestellten Gerbsäuren, welche in einer Reinheit und zu einem so billigen Preise im Handel sind, daß die Anwendung von gerbsäure-

1) Die Chemie der natürlichen Farbstoffe von Dr. H. Rupe, Vieweg-Braunschweig 1900. - Vgl. auch MI uspratts Technische Chemie, IV. Aufl., 3, 132-298. 
haltigen Materialien nur in einzelnen Fällen, z. B. bei Sumach, noch Vorteil bietet. Außer der technischen Gerbsäure werden auch immer mehr Extrakte verwendet, z. B. Sumachextrakt, Kastanienholzextrakt zur Herstellung von Schwerschwarz auf Seide. Gegen die Verwendung von durch Eindampfen konzentrierten Extrakten ist im Prinzip nichts einzuwenden, wenn die Extrakte, abgesehen von einem dem Preis entsprechenden Gehalte an Gerbsäure, keine oder nur geringe Mengen von Gallussäure, welche leicht aus Gerbsäure entsteht, enthalten. Denn Gallussäure ist für die meisten Farboperationen nicht nur wertlos, sondern sogar nachteilig. Da die Gerbsäuren mit den basischen Farbstoffen unlösliche Verbindungen bilden, so werden sie als Beize beim Färben mit diesen Farbstoffen verwendet. Diese Eigenschaft verliert die Gerbsäure nicht, wenn sie vor dem Färben auf der Faser in ein unlösliches Salz verwandelt worden ist durch Behandlung mit Lösungen von Brechweinstein, neutralem Alaun, Zinnchlorid usw. Da die in diesen unlöslichen Gerbsäureverbindungen enthaltenen Metalloxyde auch mit den sogenannten Beizenfarbstoffen unlösliche Farblacke bilden, so dient die Gerbsäure nicht nur als Beize, sondern auch als Befestigungsmittel für andere Beizen, so daß die mit Gerbsäure und den genannten Metalloxyden behandelten Fasern nicht nur mit den Farbstoffbasen, sondern auch mit einer großen Anzahl anderer Farbstoffe, z. B. den Alizarinfarbstoffen, den wichtigsten Vertretern der Beizenfarbstoffe, gefärbt werden können. Da nun eine Lösung von Gallussäure Eisenoxydsalze zu Oxydulsalzen reduziert, und die gallussauren Salze des Aluminiums, Antimons und Eisenoxyduls in Wasser löslich sind, so kann die Gallussäure nicht als Befestigungsmittel dienen; da aber ihre Bildung aus Gerbsäure sehr leicht vor sich geht, so findet sie sich stets in größerer oder geringerer Menge in den Extrakten des Handels vor. Wenn die Farben, welche mit Hilfe von Gerbsäure hergestellt werden, rein und klar sein sollen, so kann die Anwesenheit von Farbstoffen in den Gerbsäurematerialien und Extrakten nur nachteilig wirken; man wird in diesem Falle die besten und schönsten Resultate durch Anwendung von reiner Gerbsäure erzielen. Bei der Herstellung von Schwarz und überhaupt der meisten Mischfarben werden jedoch die in den Gerbsäurematerialien und Extrakten stets vorhandenen Farbstoffe mitwirken, so daß für diese Art der Färberei nicht nur die Menge der Gerbsäure, sondern außer dem Vorhandensein von nur wenig Gallussäure auch die Menge und die Art der
Farbstoffe in den Materialien in Betracht kommt. Welcher Art diese Farbstoffe in den verschiedenen Gerbsäurematerialien sind, ist bis jetzt noch ganz unaufgeklärt. Da sie jedoch für den Färber von großer Wichtigkeit sind, so muß ihre Anwesenheit und die Art und Weise, wie sie bei der Verwendung wirken, bei der Beurteilung und Wertbestimmung berücksichtigt werden.

Die gebräuchlichen Untersuchungsmethoden für die Gerbsäurematerialien geben nur Aufschlub uiber die in der Gerberei zur Wirkung kommenden Substanzen und geben nicht immer übereinstimmende Resultate, wie vor kurzem von Gulden²) beklagt worden ist, selbst weun man genau nach den von dem Internationalen Verein der Lederindustriechemiker vorgeschriebenen Bedingungen arbeitet (Leitfaden für gerbereichemische Untersuchungen von Procter-Paeßler S.122). Für den Färber liefern diese Methoden nur unvollständige Resultate, da er auch Aufschluß über die Art der außer der Gerbsäure vorhandenen Farbstoffe haben mub. Diesen kann er sich nur durch einen Färbeversuch verschaffen, welcher mit dem zu beurteilenden Material im Vergleich mit reiner Gerbsäure oder einem mustergültigen Material ausgeführt wird. Man vergleicht am richtigsten inmer Gleiches mit Gleichem, also Sumach, Galläpfel oder Gerbsäure stets mit mustergültigem Sumach, Galläpfeln oder Gerbsäuren, wird jedoch mit einer für die Praxis genügenden Genauigkeit den Wert eines Sumachs oder der Galläpfel auch durch Vergleich mit reiner Gerbsäure ermitteln können.

Da Gerbsäure fast ausschließlich zum Färben oder Beizen von Baumwolle dient, so verwendet man für das Probefärben ein dünnes Baumwollgewebe, welches durch Kochen mit Sodalösung von der Appretur befreit worden ist. Baumwollene Gewebe dürfen nicht durch Auspressen mit der Hand entnäßt werden, sondern es muß durch Abpressen zwischen Filtrierpapier geschehen, man erhält dann auch bei Farbversuchen im kleinen mit 3 bis $5 \mathrm{~g}$ Baumwollenstoff vollkommen gleichmäßige Färbungen. Preßt man die Muster jedoch in der Hand aus, so entstehen in den dadurch entstandenen Druckfalten stets hellere Färhungen, und man erbält Muster, welche für die Wertbestimmung ganz ungeeignet sind.

Da hier nicht der Platz für eine genaue Ausführungsbeschreibung des Probefärbens ist ${ }^{3}$ ), so sollen nur einige Angaben über die in Arbeit zu nehmenden Mengen der Gerbsäurematerialien, Faserstoffe und Lösungs-

2) Diese Z. 1904, 1.

3) Musspratt, Technische Chem., IV. Aufl., 3, 120 
mittel gemacht werden; gerade die Menge des Lösungsmittels muß für das Probefärben mit Gerbsäuren genau eingehalten werden, da sie dem Farbbad nicht vollständig, sondern nur entsprechend der Menge des angewendeten Fasermaterials entzogen werden. Es ist deshalb unbedingt notwendig, daB zur Herstellung der Vergleichsskala und der Probefärbung dieselbe Menge Baumwolle und Wasser, sowie ein Quantum Gerbsäurematerial, welches eine innerhalb der Vergleichsskala liegende Farbentiefe liefert, verwendet wird. Bei Farbstoffen, welche aus den Farbflotten vollständig ausgezogen werden, ist dieses genaue Einhalten einer Vorschrift nicht nötig. Die folgende Vorschrift ist für die Anwendung von dïnnen, von Appretur gut befreiten Kattun bestimmt.

Für die Herstellung der Vergleichsskala wird der Wassergehalt einer nicht mehr als $5 \%$ Nichtgerbstoffe enthaltenden Gerbsäure durch Trocknen bei $105^{\circ}$ ermittelt und hierauf von derselben Gerbsäure ein Quantum, welches genau $3 \mathrm{~g}$ Trockensubstanz entspricht, in $1 \mathrm{l}$ Wasser aufgelöst. Je

$1 \mathrm{ccm}, 2 \mathrm{ccm}, 3 \mathrm{ccm}, 4 \mathrm{ccm}, 5 \mathrm{ccm}, 6 \mathrm{ccm}$, $7 \mathrm{ccm}, 8 \mathrm{ccm}, 9 \mathrm{ccm}, 10 \mathrm{ccm}$

dieser Lösung wird mit $200 \mathrm{ccm}$ Wasser von $50^{\circ}$ in einem Becherglas verdünnt, die gut angenäßten, nicht gedrückten Baumwollstreifen zu je $2 \mathrm{~g}$ eingelegt, zuweilen umgezogen und 12 Stunden darin gelassen. Hierauf werden die Streifen zwischen Filtrierpapier lose ausgepreßt und in $200 \mathrm{ccm}$ einer $40^{\circ}$ warmen Lösung von $0,75 \mathrm{~g}$ kristallisiertem Eisenvitriol in $1000 \mathrm{ccm}$ Wasser 15 Minuten lang eingelegt, ohne zu drücken gespült und getrocknet. Für die Wertbestimmung der einzelnen Ger̨bsäurematerialien werden alsdann

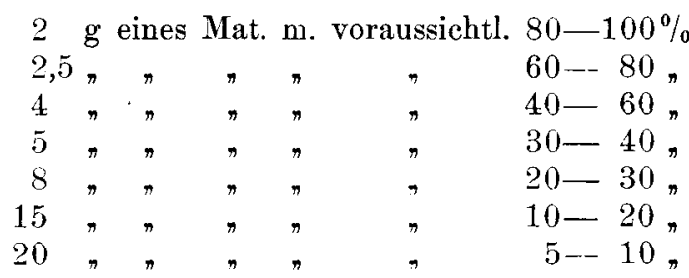

Gerbsäure abgewogen, 5--6 mal mit Wasser in einer Schale ausgekocht, die vereinigten Lösungen auf $1 \mathrm{l}$ aufgefüllt und durch Glaswolle filtriert. Mit je $5 \mathrm{ccm}$ und $10 \mathrm{ccm}$ dieser Lösung werden in der angegebenen Weise die Probefärbungen hergestellt und ihre Färbung mit der Vergleichsskala verglichen. Die hellere Fürbung mit 5 ccm Abkochung stellt man her, um auch bei Nichtkenntnis der ungefähren Färbekraft des zu untersuchenden Materials einen in die Vergleichsskala fallenden Farbenton zu erhalten.
Wenn man z. B. $5 \mathrm{~g}$ Galläpfel auf $1 \mathrm{l}$ Wasser ausgekocht hat, so daB $10 \mathrm{ccm}$ Lösung $0,050 \mathrm{~g}$ Galläpfel und $5 \mathrm{ccm}$ Lösung $0,025 \mathrm{~g}$ Galläpfel entsprechen, und die damit hergestellten Färbungen stimmten mit den mit $9 \mathrm{ccm}$, resp. 4-5 ccm der Skala erhaltenen Färbungen überein, so hatten $0,05 \mathrm{~g}$ Galläpfel denselben Farbwert wie $0,027 \mathrm{~g}$ Tannin, oder die Galläpfel hatten $54 \%$ des Farbwertes des zur Vergleichsskala verwendeten Tannins. Bei einiger Übung kann man trotz manchmal vorhandener großer Mengen von Nebenfarbstoffeu iiber die richtige Färbung nicht im Zweifel sein; man wird meistens finden, daß die durch Probefärben erhaltenen Resultate mit der durch Titrieren mit übermangansaurem Kalium gefundenen Menge Gerbsäure übereinstimmen, wenn man die Gesamtmenge der für die Gerbsäuren und sogenannten Nichtgerbsäuren verbrauchten Menge übermangansaures Kalium in Rechnung stellt.

Catechu oder Japanische Erde wird als Grundfarbe für dunkle Färbungen und zur Herstellung eines sehr licht- und waschechten Braun auf Baumwolle, besonders für Brotbeutel, Zeltstoffe usw. für den Armeebedarf verwendet. Über die in diesem Material enthaltenen Verbindungen hat der Verfasser schon vor längerer Zeit eine Ansicht $\$$ ) ausgesprochen, welche später von $\mathrm{Hummel}$ und Brown ${ }^{5}$ ) bestätigt worden ist. In der frisch bereiteten Abkochung des Holzes der Catechuakazie kann Catechin wegen seiner geringen Löslichkeit nicht enthalten sein $(1 \mathrm{~g}$ Catechin löst sich in $1200 \mathrm{~g}$ kaltem und 2-3 g kochendem Wasser). Wahrscheinlich enthält der Saft eine glukosidartige Verbindung des Catechins, also eine ähnliche Verbindung, wie die, in denen das Hämatoxylin in dem Campecheholz, die Krappfarbstoffe in der frischen Krappwurzel und mehrere andere Pflanzenfarbstoffe in den Pflanzensäften enthalten sind. Während des Eindampfens des Saftes tritt ein Zerfallen dieser Verbindung in Glukose und Catechin ein, welches dann unter Wasserabspaltung zum Teil in die in Wasser leicht lösliche Catechugerbsäure und andere in Wasser schwer- oder unlösliche Körper, die Japonsäure, Rubinsäure usw. genannt worden sind, übergeht. Die wichtigsten Stoffe in dem Catechu sind die Catechugerbsäure und das Catechin.

Die Catechugerbsäure gibt mit Brechweinstein einen hellgelben Niederschlag, fällt Alkaloide und Leimlösung und verbindet sich mit tierischer Haut. Catechin gibt jedoch

4) Monatsschr. f. Text.-Ind. 1888, 241.

$5)$ J. Soc. Chem. Ind, 15, 422, - Chem. Centralbl. 1896, II, 371. 
mit Lösungen von Leim, Brechweinstein und Alkaloiden keine Niederschläge. Wenn man reines Catechin mit dichromsaurem Kalium behandelt, so tritt nur nach einiger Zeit eine Rotfärbung ein, während bei der gleichen Behandlung von Catechugerbsäure sofort ein starker rotbrauner Niederschlag entsteht. Dementsprechend erzielt man auch bei der gewöhnlichen Färbemethode (bei der nachträglichen Behandlung der Stoffe mit chromsaurem Kalium) mit reiner Catechugerbsäure ein schönes Braun, mit reinem Catechin jedoch so gut wie gar keine Färbung, selbst wenn das Catechu, welches zur Herstellung dieses Catechins gedient hat, ein schönes Braun gibt. Wenn man ferner noch die allgemeine Erfahrung berücksichtigt, daß der durch Erhitzen auf $130^{\circ}$ dargestellte präparierte $\mathrm{Ca}$ techu eine größere Färbekraft besitzt als der gewöhnliche Catechu, und $\mathrm{daß}$ ein mit $\mathrm{Ca}$ techulösung imprägnierter Baumwollenstoff viel dunkler gefärbt wird, wenn er vor der Behandlung mit chromsaurem Kalium gedämpft worden ist, so erscheint es sehr wahrscheinlich, daß nicht das Catechin, sondern die Catechugerbsäure, welche teils in dem Catechu enthalten, teils während des Färbeprozesses aus dem Catechin entstanden ist, als derjenige Körper angesehen werden muß, welcher dem Catechu die Färbekraft erteilt. Durch das Präparieren des Catechus geht wahrscheinlich das Catechin, welches durch Behandlung mit chromsaurem Kalium nicht in braune unlösliche Körper (Japonsäure, Rubinsäure) verwandelt wird und deshalb beim Färben nicht zur Geltung kommt, durch Wasserabspaltung in die von $\mathrm{Etti}^{6}$ ) dargestellten Anhydride über, die sich gegenüber chromsaurem Kalium wie Catechugerbsïure verhalten und Baumwolle wie dieser Körper färben. Demnach ist die Verwendung von Catechu, welcher nicht durch Erhitzen auf etwa $130^{\circ}$ präpariert worden ist, als sehr unvorteilhaft zu bezeichnen.

Der Wert des Catechus, welcher sehr oft mit den mannigfaltigsten Beimischungen verfälscht und oft nur nach seiner äuberen Beschaffenheit, nach Härte, Farbe, Geschmack, nach seiner Löslichkeit in Wasser, Weingeist usw. beurteilt wird, kann durch Titrieren mit übermangansaurem Kalium mit Indigo. lösung als Indikator nicht ermittelt werden. Der Verbrauch an übermangansaurem Kalium gibt wohl einen Maßstab für die Menge derjenigen Stoffe, welche unter den bei diesem Versuche eingehaltenen Bedingungen oxydiert werden können, er entscheidet jedoch nicht die Frage, ob diese Stoffe für den Färber

\footnotetext{
6) Ann. Chim. 186, 332 .
}

wertvoll sind oder nicht. Diese Frage kann wiederum nur durch einen Färbeversuch im kleinen entschieden werden.

Da die Catechugerbsäure nur ensprechend der Konzentration des Bades von der Baumwolle aufgenommen wird, so müssen, ebenso wie bei den Probefärbungen mit Gerbsäure, die Mengen des Lösungsmittels und der Baumwolle genau eingehalten werden. Für die Vergleichsskala färbt man zehn Baumwollenmuster à $2 \mathrm{~g}$ mit von $1,5-15 \%$ gleichmäßig zunehmenden Mengen eines guten Catechus, wobei berücksichtigt werden muß, ob derselbe präpariert ist, oder mit $0,15-1,5 \%$ reiner Catechugerbsäure, welche man nach Löwe ${ }^{7}$ ) aus Catechu herstellen oder aus einer chemischen Fabrik beziehen kann. Von dem zu beurteilenden Catechu färbt man in derselben Weise ein helles Muster mit 7,5\% und ein dunkles Muster mit 15\% Catechu. Für 2 g Baumwolle verwendet man $200 \mathrm{ccm}$ Wasser, behandelt darin die Baumwolle etwa eine Stunde bei $90-100^{\circ}$, läßt die Muster in dem Bad erkalten, prebt die Baumwollstreifen zwischen Filtrierpapier ab und legt sie 20 Minuten lang in $200 \mathrm{ccm}$ einer Lösung von $1 \mathrm{~g}$ dichromsaurem Kalium in $1 \mathrm{l}$ Wasser ein.

Unter den Farbhölzern hat von jeher das Blauholz eine hervorragende Stelle eingenommen und behauptet dieselbe noch immer, besonders wegen seines billigen Preises. Das billigste Schwarz für Wolle ist heute noch das Chromschwarz und für Baumwolle das Eisenschwarz; außerdem gibt auf Wolle kein künstlicher Farbstoff ein so schönes blaustichiges Schwarz, als der Blauholzehromlack, und auch in bezug auf Echtheit ist das Blauholzschwarz den meisten billigen Produkten aus dem Steinkohlenteer überlegen. Noch in Anfang des vorigen Jahrhunderts wurde nur geraspeltes $\mathrm{Holz}$ verwendet; die Errichtung der ersten Extraktfabriken fällt in die Jahre zwischen 1830 und 1840 , und heute werden sehr bedeutende Mengen von Extrakten besonders in Amerika, Frankreich, Deutschland und der Schweiz hergestellt. Über den Wert dieser Fabrikate, besonders der amerikanischen und deutschen Extrakte war man früher sehr verschiedener Ansicht ${ }^{8}$ ), heute kann man wohl behaupten, daß die deutschen Fabriken imstande sind, mindestens ebenso gute Fabrikate zu liefern, als die aller anderen Länder, aber auch, daß reine. Extrakte nur äuBerst selten in den Handel kommen, und daß fast alle Handelsprodukte, namentlich die sogenannten Konkurrenz-

7) J. prakt. Chem. 105, 75.

${ }^{8}$ Monatsschr. f. Text.-Ind. 1890, Heft 11. 
produkte, versetzt sind mit Melasse, Gerbsäureextrakten, besonders Quebracho- und Kastanienholzextrakt.

Aus Unkenntnis über die beim Färben in Betracht kommenden chemischen Reaktionen waren die Färber früher der Ansicht, daß die Extrakte nur zum Färben von Baumwolle verwendet werden könnten, und daß zum Färben der Wolle, namentlich für Chromschwarz, nur die Abkochungen von gut fermentiertem Holz brauchbar seien. Eine Verfolgung der chemischen Prozesse, welche beim Färben dieser beiden Faserarten beachtet werden müssen, erklärt leicht den Grund für diese Annahme, aber auch ihre Unrichtigkeit ${ }^{9}$.

In dem Safte des frisch geschlagenen Blauholzes befindet sich, wie in dem der Catechuakazie, der frischen Krappwurzel und vielen anderen farbstoffhaltigen Pflanzensäften, die Verbindung einer Glukoseart mit Hämatoxylin, welche an sich keine fürbenden Eigenschaften besitzt. Dieses Glukosid mub zuerst in Glukose und Hämatoxylin gespalten und das letztere durch Oxydation in Hämateïn übergeführt werden. Die Spaltung des Glukosides erfolgt bei der Fermentation des geraspelten Holzes oder während der Konzentration seiner Abkochungen zu flüssigen und festen Extrakten; die Oxydation des Hämatoxylins tritt während dieser beiden Prozesse durch die Wirkung des Sauerstoffs der Luft ein, oder es muß während des Färbeprozesses die Möglichkeit hierzu vorhanden sein. Da jedoch dieser Oxydationsprozeb des nichtfärbenden Hämatoxylins mit der Entstehung des färbenden Hämateïns nicht abschließt, sondern da bei unvorsichtiger Fermentation und beim Eindampfen Überoxydationsprodukte entstehen, welche entweder in Wasser unlöslich sind oder die Faser gelb und braun färben, so ist der Wert des Farbmaterials von der Sorgfalt abhängig, mit welcher diese beiden Operationen ausgeführt worden sind. $\mathrm{Da}$ diese Überoxydation sich nur auf das Hämateïn erstreckt, so ist es erklärlich, daß man bei der Herstellung von Extrakten den während der Fermentation eintretenden Oxydutionsprozeß nicht zu weit gehen lassen darf, und da $\beta$ alle Extrakte, selbst wenn sie aus "gut fermentiertem" Holz dargestellt sein sollen, inmer vorzugsweise Hämatoxylin und wenig Hämateïn enthalten. Dieses ist auch der Grund dafür, daß man früher die Extrakte zur Herstellung von Chromschwarz auf Wolle nicht verwenden wollte, sondern nur die Abkochungen von fermentiertem Holz für geeignet hielt. Beim Schwarzfärben der Baumwolle wird die Faser vor-

9) Monatsschr. f. Text.-Ind, 1890, Heft 12. her mit Eisensalzen behandelt; das dadurch befestigte Eisenoxyd kann mit Hämateïn direkt den schwarzen Farblack bilden oder vorher, da Eisenoxyd stets in genügender Menge vorhanden ist, die Oxydation des Hämatoxylins zu Hämateïn bewirken. Deshalb konnte der Baumwollenfärber die bequem anzuwendenden Extrakte gebrauchen. Zum Färben der Wolle wird diese vorher mit dichromsaurem Kalium und Weinstein gebeizt, so daß auf einer in richtiger Weise und ohne die nicht beabsichtigte Wirkung anderer Körper gebeizten Wolle sich Chromoxyd und Chromsäure befindet; das in dem Farbmaterial enthaltene Hämateïn kann sich direkt mit dem nichtoxydierenden Chromoxyd vereinigen, während das Hämatoxylin durch die Chromsäure oxydiert werden kann. Infolge der ungenügenden Reinigung der Wolle, namentlich aber durch die Anwesenheit großer Mengen von organischen Stoffen in den Farbwässern kann jedoch bereits während des Beizens alle Chromsäure reduziert werden, so daß die gebeizte Wolle nur Chromoxyd enthält, welches das Hämatoxylin unberührt läßt. Da Extrakte nur wenig Hämateïn enthalten, so kommt das Hämatoxylin bei "grüngebeizter Wolle" nicht zur Wirkung. Deshalb zog der Wollfärber Abkochungen von fermentiertem Holz vor, welches größere Mengen von Hämateïn enthält, da die Abkochungen nicht konzentriert werden, so $\mathrm{da} B$ eine Überoxydation nicht eintritt.

Dieses Verhalten der keinen Farblack bildenden oxydierenden Chromsäure und des einen Farblack bildenden nicht oxydierenden Chromoxyds kommt in derselben Weise wie beim Färben mit Blauholz auch bei vielen anderen Farbmaterialien in Betracht. Beim Färben mit Alizarinfarbstoffen und vieler anderer Beizenfarbstoffe wird die Wolle noch vielfach mit dichromsaurem Kalium und Weinstein gebeizt, trotzdem das Alizarin, Flavopurpurin, Anthrapurpurin, ferner das Alizarinblau, Cöruleïn, Galleïn usw. zur Farblackbildung mit Chromoxyd keiner vorausgehenden Oxydation bedürfen, und man weit reinere und schönere Färbungen erhält, wenn man die Wolle mit Chromfluorid und Weinstein beizt, wodurch nur Chromoxyd auf ihr abgelagert wird. Dagegen kann beim Färben mit Catechu das chromsaure Salz nicht durch ein Chromoxydsalz ersetzt werden, weil hier eine Oxydation der Catechugerbsäure und nicht die Bildung einer Chromoxydverbindung bewirkt werden soll. Auch der FärbeprozeB mit Rotholz scheint, wie später noch angegeben werden wird, auf ähnlichen Prozessen zu beruhen, wie der des Blauholzes. 
Für die Wertbestimmung des Blauholzes und seiner Extrakte durch Probefärben müssen dieselben Reaktionen berücksichtigt werden, welche bei der Anwendung maßgebend sind. Hämateïn muß auf der zu färbenden Wolle Chromoxyd vorfinden, um damit den Farblack zu bilden ohne eine Überoxydation zu erleiden, und für das Hämatoxylin muß Chromsäure vorhanden sein, damit dieser nichtfärbende Körper zu färbendem Hämateïn oxydiert werden kann. Deshalb muß die Wolle mit dichromsaurem Kalium umd einem schwachen Reduktionsmittel, am besten Weinstein, vorher gebeizt werden. $\mathrm{Da}$ eine $\mathrm{Ab}$ schätzung der Farbentöne nur bei nicht zu dunkeln Farben möglich ist, und die Farbbäder ausgefärbt sein müssen, so darf nur so viel Farbmaterial angewendet werden, dab nur blaue und nicht schwarze Farben entstehen. Infolgedessen darf auch kein zu großer Überschuß von Chromsäure in der gebeizten Wolle enthalten sein; denn man kann sich leicht durch einen Versuch davon überzeugen, daß diejenigen Mengen von dichromsaurem Kalium $(3 \%$ vom Wollengewicht), welche zur Erzeugung von Chromschwarz auf Wolle im großen nötig sind, mit den geringen Farbstoffmengen, welche zur Herstellung von blauen, für eine Wertbestimmung geeigneten Chromlacken genügen, Mißfarben erzeugen, weil ein großer Teil des Farbstoffs überoxydiert wird. Aus diesem Grunde sind die Probefärbungen der Extrakthändler als Wertbestimmungen unbrauchbar, wenn sie, wie dieses sehr oft geschieht, mit Wolle ausgeführt werden, welche in einer Färberei mit der oben angegebenen Menge von chromsaurem Kalium gebeizt worden ist; derartige Ausfärbungen können ebenso wie die auf die sogenannten Elsässer Garanzinestreifen hergestellten nur Aufschluß geben über die Nuancierung des mit dem Extrakt herzustellenden Schwarz.

Am besten eignet sich ein dünnes Wollengewebe, welches zur Ermittlung der Gesamtmenge des Hämatoxylins und des Hämateïns mit $1 \%$ dichromsaurem Kalium und $2 \%$ Weinstein etwa eine Stunde lang in kochendem Bade gebeizt worden ist. Zur Herstellung der Vergleichsskala färbt man mit dieser gebeizten Wolle zehn gleichschwere Streifen mit $0,05 \%-0,10 \%-0,15 \%-0,20 \%$ $-0,25 \%-0,30 \%-0,35 \%-0,40 \%$ - $0.45 \%$ - $0,50 \%$ reinem Hämatoxylin, welches in schönen strohgelben Kristallen durch Umkristallisieren leicht herzustellen ist. Wenn auch die Menge des Hämateïns bestimmt werden soll, so bedarf man noch einer Vergleichsskala, welche mit denselben Mengen Hämateïn auf chromoxydgebeizter Wolle (her- gestellt durch einstündiges Kochen der Wolle mit $3 \%$ Chromfluorid und $3 \%$ Weinstein) gefärbt worden ist. Das Hämateïn stellt man sich nach Erdmann (J. prakt. Chem. 26, 205) durch vorsichtige Oxydation von reinem Hämatoxylin, welches in wasserhaltigem $\ddot{A}$ ther gelöst ist, mit Salpetersäure her. Für die Probefärbung stellt man auf Wolle, welche sowohl Chromoxyd als auch Chromsäure enthält, und ebenso auf Wolle, welche nur Chromoxyd enthält, eine helle und eine dunkle Färbung her. Die Menge des hierzu nötigen Farbmaterials ist abhängig von seinem Farbstoffgehalt, gewöhnlich braucht man 0,5 und $1 \%$ festen Extrakt, 1 und $2 \%$ flüssigen Extrakt, 2,5 und $5 \%$ gutes nicht verdorbenes Holz, 5, 10 und $20 \%$ schlechtes verdorbenes Holz. Eine größere Menge der Materialien wird öfter mit Wasser ausgekocht, die Lösungen vereinigt, auf ein bestimmtes Volumen mit Wasser verdünnt und filtriert. Von der filtrierten Lösung verwendet man ein den angegebenen Mengen entsprechendes Volumen zu den Färbungen. Man legt die gebeizten und gut durchfeuchteten Wollmuster bei gewöhnlicher Temperatur in das Farbbad, bringt innerhalb einer halben Stunde zum Kochen und kocht noch eine halbe Stunde lang.

Es waren $5,53 \mathrm{~g}$ fester Extrakt in 11 Wasser gelöst und die Wollmuster wogen 5 g. Zwei Muster wurden mit $5 \mathrm{ccm}=$ $27,75 \mathrm{mg}=0,553 \%$ Extrakt gefärbt und zwei andere mit der doppelten Menge, also mit 1,106\% Farbmaterial. Die Farbe des hellen Musters, welches mit Chromsäure und Chromoxyd gebeizt war, paßte zwischen die Muster Nr. 3 (gefärbt mit $0,15 \%$ Hämatoxylin) und Nr. 4 (gefärbt mit $0,20 \%$ Hämatoxylin) und diejenige des einen dunklen Musters, welches ebenso gebeizt war, stimmte mit Nr. 7 (gefärbt mit 0,35\% Hämatoxylin) der ersten Vergleichsskala überein. Demnach hatten 1,106 Teile des Extrakts denselben Farbwert wie 0,35 Teile Hämatoxylin, er enthielt also $31,7 \%$ Hämatoxylin und Hämateïn. Da ferner die Färbung mit 1,106\% Extrakt auf Wolle, welche nur mit Chromoxyd gebeizt war, zwischen die Muster Nr. 1 und 2 der zweiten Skala fiel, so haben hierbei 1,106 Teile Extrakt denselben Farbwert gehabt wie 0,075 Teile Hämateïn, er enthielt also $6,8 \%$ Hämateïn und $31,7-6,8$ $=24,9 \%$ Hämatoxylin. Da jedoch während des einstündigen Färbeprozesses immer ein Teil des Hämatoxylins in Hämateïn übergeht, so daß ein mit Chromoxyd gebeiztes Wollmuster, welches mit reinen Hämatoxylin gefärbt worden ist, trotz der Abwesenheit der Chromsäure schwach blau gefärbt wird und 
in der Färbung mit Nr. 1 der Hämateïnchromoxydskala übereinstimmt, so muB die dieser Färbung entsprechende Menge $\mathrm{Hä-}$ mateïn in Abzug gebracht werden, da sie erst während des Färbeprozesses entstanden ist. Es müssen demnach für 1,106 Teile Extrakt 0,05 Teile, oder für 100 Teile Extrakt 4,5 Teile abgezogen werden. Der Extrakt enthielt also $6,8-4,5=2,3 \%$ Hämateïn und $31,7-2,3=29,4 \%$ Hämatoxylin.

$\mathrm{Da}$ die Extrakte selten in reinem $\mathrm{Zu}$ stande im Handel vorkommen, sondern mei- stens mit Melasse, Kastanienholz- und Quebrachoholzextrakt vermischt sind, so ist der Nachweis dieser Zusätze sehr oft von Wichtigkeit. Einen guten Anhalt bietet hierbei die Menge der auf wasserfreie Substanz berechneten Asche, da wasserfreier reiner Blauholzextrakt höchstens $1,5 \%$, meistens jedoch weniger feuerbeständige Stoffe enthält.

Über den Aschengehalt der Gerbsüureextrakte liegen nur wenige Angaben vor. Nach Mitteilung des Herrn Dr. Päßler in Freiberg enthalten die in Betracht kommenden Extrakte

\begin{tabular}{|c|c|c|c|c|c|}
\hline & & Wasser & $\begin{array}{l}\text { Gerbende } \\
\text { Stoffe }\end{array}$ & Mineralstoffe & $\begin{array}{c}\text { Mineralstoffe } \\
\text { auf wasserfreie } \\
\text { Substanz } \\
\text { berechnet }\end{array}$ \\
\hline $\begin{array}{c}\text { Kastanienholzextrakt, flüssig } \\
\text { teigförmig . }\end{array}$ & $\begin{array}{ll}\cdot & \cdot \\
\cdot & \cdot\end{array}$ & $\begin{array}{l}62-58 \% \\
54-50 \%\end{array}$ & $\begin{array}{l}24-28 \% \\
35-40 \%\end{array}$ & $\begin{array}{l}0,4-1,0 \% \\
0,6-1,2 \%\end{array}$ & \} $1,5-3,5 \%$ \\
\hline $\begin{array}{cc}\text { Quebrachoholzextrakt, flüssig } \\
\text { teigförmig } \\
n & \text { fest. . }\end{array}$ & $\begin{array}{ll}\cdot & \cdot \\
\cdot & \cdot \\
\cdot & \cdot\end{array}$ & $\begin{array}{l}62-56 \\
56-48 \\
23-16\end{array}$ & $\begin{array}{l}30-38 \\
36-45 \\
60-72\end{array}$ & $\begin{array}{l}0,4-1,0 \\
0,5-1,2 \\
0,6-1,5\end{array}$ & $\{1,0-2,5 \%$ \\
\hline
\end{tabular}

Bei diesen gewöhnlich als Zusatz verwendeten Extrakten wird demnach der Aschengehalt einer Mischung mit Blauholzextrakt nicht beeinflußt; bei den übrigen Gerbsäureextrakten, welche jedoch nicht verwendet werden, Fichtenholz-, Myrobalanen-, Sumach-, präparierter kaltlöslicher Quebrachoholzextrakt, Gambir usw. beträgt die auf wasserfreie Substanz berechnete Aschenmenge 5 bis $18 \%$.

Dagegen übt einen sehr großen Einfluß auf den Aschengehalt der verschnittenen Extrakte der Zusatz von Melasse aus, welche ungefähr aus $50 \%$ Zucker, $30 \%$ anderer fester Stoffe und $20 \%$ Wasser besteht und bei diesem Wassergehalt etwa $10 \%$ Asche hinterläßt. Ein Zusatz von Melasse kann bei festen Ex- trakten sehon daran erkannt werden, dab sie sich schlecht pulverisieren lassen und nach kurzer Zeit bei gewöhnlicher Temperatur zu einer zusammenhängenden Masse zusammenfließen. Während ferner die Asche eines reinen Blauholzextraktes wei $\beta$, sehr locker und leicht ist, liefert ein mit Melasse versetzter Extrakt stets eine geschmolzene und meistens dunkelgefärbte Asche, welche, auf wasserfreien Extrakt berechnet, viel mehr als $1,0 \%$ beträgt. Ein Blauholzextrakt, welcher aus $40 \%$ Wasser und $60 \%$ festen Stoffen mit 1,2\% Asche besteht, und Melasse, welche $20 \%$ Wasser und $80 \%$ feste Stoffe $(50 \%$ Zucker, $30 \%$ andere organischeStoffe mit $10 \%$ Asche) enthält, geben Mischungen von ungefähr folgender Zusammensetzung:

\begin{tabular}{|c|c|c|c|c|c|c|c|c|c|c|c|}
\hline & & & & & & & \multirow{2}{*}{ Wasser } & \multicolumn{2}{|c|}{$\begin{array}{c}\text { Der wasserhaltige Ex- } \\
\text { trakt enthält }\end{array}$} & \multicolumn{2}{|c|}{$\begin{array}{l}\text { Der wasserfreie Ex. } \\
\text { trakt enthailt }\end{array}$} \\
\hline & & & & & & & & Asche & Zucker & Asche & Zucker \\
\hline 100 & Teile & Extrakt & und 25 & Teile & Melasse & . & $36 \%$ & $3,0 \%$ & $12,5 \%$ & $4,5 \%$ & $15,6 \%$ \\
\hline$r$ & , & , & . 50 & , & , & . & 33 & 4,2 & 17,0 & 6,2, & 25,0 \\
\hline$\pi$ & $\pi$ & $\pi$ &,$\quad 100$ & $r$ & $n$ & . & 30 & 5,6 & 25,0 & 8,0 & 36,0 r \\
\hline
\end{tabular}

Hiernach wird schon die Menge der Asche, besonders wenn man sie auf wasserfreie Substanz berechnet, und ihr Aussehen ohne weiteres Aufschlub über den Zusatz von Melasse geben.

Der Zusatz von Melasse kann jedoch, wenn auch nicht dem Gewichte nach genau, aber doch annähernd direkt nachgewiesen werden. Hierzu ist gefälltes Eisenoxydhydrat sehr geeignet. Man versetzt eine chlorammoniumhaltige Lösung von $90 \mathrm{~g}$ kristallisiertem Eisenalaun mit überschüssigem Ammoniak, wäscht mit Hilfe einer selbsttätigen Auswaschvorrichtung das Eisenoxydhydrat auf einem glatten Filter bis zum Verschwinden der Chlorreaktion aus, spült es in ein Litergefï $B$ und füllt bis zur Marke mit Wasser. In $50 \mathrm{cem}$ ist $1 \mathrm{~g}$ Eisenoxydhydrat in Suspension. Durch dasselbe wird das Hämatoxylin zu Hämateïn oxydiert und dieses als Hämateïneisenoxyd ausgefällt.

$$
\begin{gathered}
\mathrm{C}_{16} \mathrm{H}_{3}(\mathrm{OH})_{6} \cdot \mathrm{H}_{2} \mathrm{O}+\mathrm{Fe}_{2}(\mathrm{OH})_{6}=\mathrm{C}_{16} \mathrm{H}_{6}(\mathrm{OH})_{6} \\
+2 \mathrm{Fe}(\mathrm{OH})_{2}+3 \mathrm{H}_{2} \mathrm{O} \\
2 \mathrm{Fe}(\mathrm{OH})_{2}+2 \mathrm{Fe}_{2}(\mathrm{OH})_{6}=2 \mathrm{Fe}_{3}(\mathrm{OH})_{8} \\
\mathrm{C}_{16} \mathrm{H}_{66}(\mathrm{OH})_{6}+\mathrm{Fe}_{2}(\mathrm{OH})_{6,}=\mathrm{C}_{16} \mathrm{H}_{6} \mathrm{O}_{66} \mathrm{Fe}_{2}+6 \mathrm{H}_{2} \mathrm{O} \\
\mathrm{C}_{16} \mathrm{H}_{8}(\mathrm{OH})_{66}+4 \mathrm{Fe}_{2}(\mathrm{OH})_{6}=\mathrm{C}_{16} \mathrm{H}_{6} \mathrm{O}_{6} \mathrm{Fe}_{2} \\
+2 \mathrm{Fe}_{3}(\mathrm{OH})_{6}+9 \mathrm{H}_{22} \mathrm{O}
\end{gathered}
$$


320 Teile kristallisiertes Hämatoxylin brauchen 214 Teile Eisenoxydhydrat, also 0,5 Teile $\mathrm{C}_{16} \mathrm{H}_{8}(\mathrm{OH})_{t ;} \cdot \mathrm{H}_{2} \mathrm{O}, \quad 1,34$ Teile $\mathrm{Fe}_{2}(\mathrm{OH})_{b}$. Durch das Eisenoxydhydrat werden ferner auch die Gerbsäure, fast alle Gallussäure und aus der Melasse fast alle Nichtzuckerverbindungen ausgefällt; leider wird aber dabei immer etwas Zucker abgeschieden, so daß das Verfahren nicht genau quantitativ ist. Diese Menge ist jedoch gering und abhängig von der Konzentration der Lösungen und der Menge des angewendeten Eisenoxydhydrats. Da reine Blauholzextrakte nach der Behandlung mit Eisenoxydhydrat niemals mehr als $2-2,5 \%$ nichtausfällbare Stoffe beim Eindampfen hinterlassen, und die Menge der zugesetzten Melasse niemals gering ist, so kann in dieser Weise ein Melassezusatz leicht nachgewiesen werden. Man findet meistens $20 \%$ und mehr Zucker rom wasserhaltigen Extrakt (vgl. vorige Zusammenstellung).

Man verdünnt so viel einer Extraktlösung, welche etwa $0,5 \mathrm{~g}$ Trockensubstanz entspricht, mit Wasser auf $200 \mathrm{ccm}$, fügt 100-150 ccm der Suspension von Eisenoxydhydrat in Wasser hinzu, kocht $1 / 4$ Stunde lang über der Lampe, füllt nach dem Erkalten auf $500 \mathrm{ccm}$ auf, filtriert durch ein Faltenfilter Nr. 602 von Schleicher \& Schüll, dampft in einer gewogenen Schale im Wasserbade zur Trockne, trocknet eine Stunde lang bei $100^{\circ}$ und wägt den Rückstand. Derselbe kann nach vorausgegangener Inversion noch mit Fehlingscher Lösung geprüft werden.

$\mathrm{Zu}$ dem gleichen Zwecke ist von Morpurg $0^{10}$ ) bas. kohlensaures Blei in Wasser suspendiert empfohlen worden. Dieses scheidet allerdings aus Melasselösungen, selbst im großen Überschusse angewendet, keinen Zucker $a b$, läßt jedoch auch die übrigen Bestandteile der Melasse unberührt, und die Farbstoffe des Blauholzextraktes bedürfeu eines großen Überschusses zur vollständigen Ausfällung. Außerdem ist Eisenoxydhydrat sehr viel leichter auszuwaschen, als das basisch kohlensaure Blei und verliert seiue Wirksamkeit erst nach längerer Zeit, während das kohlensaure Blei sehr bald wieder frisch hergestellt werden muß.

Mit weit geringerer Sicherheit ist der Zusatz ron Gerbsäureextrakten zu führen. Es steht hierzu nur die Reaktion mit Schwefelammonium zur Verfügung. Man setzt zu einer Lösung von $\overline{5} \mathrm{~g}$ Extrakttrockensubstanz in 1 Liter Wasser $z_{3}$ des Volumens

10) Giorn. d. Farm d. Trieste 1897. II. 355 . Chem.-Ztg. 1899, Repert. 18. an gelbem Schwefelammonium hinzu; es fällt bei reinen Extrakten unter Dunkelfärbung der Lösung ein schwacher, brauner, flockiger Niederschlag, bei gerbstoffhaltigen Extrakten sofort unter Hellfärbung ein dichter, hellgrauer, milchiger Niederschlag aus. Bei Anwendung verdünnter Lösungen, $1 \mathrm{~g}$ in 1 Liter Wasser, ist die Reaktion jedoch deutlicher; es entsteht bei reinen Extrakten nur eine gelinde, dunkle Trübung, bei gerbstoffhaltigen jedoch eine hellgefärbte, starke Trübung, welche sich in kurzer Zeit zu großen, hellen Flocken zusammenballt.

Über die von dem Verfasser vorgeschlagene Behandlung der Blauholzextraktflotten mit Ammoniak und Luft vor dem Färben ${ }^{11}$ ) ist später nichts bekannt geworden, es scheint jedoch die Oxydation des Hämatoxylins zu Hämateïn in den Extrakten zuweilen versucht zu werden. Denn die Extrakte tragen sehr oft die Bezeichnung "fermentiert "oder, aus gut fermentiertemHolz". Der Verfasser hat auch mehrmals Extrakte untersucht, welche bis $0,6 \%$ Mangan entsprechend $0,95 \% \quad \mathrm{MnO}_{2}$ oder $1,73 \% \mathrm{KMnO}_{4}$ enthielten. In diesen Extrakten befanden sich immer große Mengen unlöslicher Stoffe.

Der Wassergehalt des Holzes, welches geraspelt und fermentiert in den Haudel kommt, ist sehr schwankend und kann bei gutem, nicht verdorbenem $\mathrm{Holz} 8-36 \%$ betragen. Die Probefärbung ist hier allein maßgebend, obwohl auch die Farbe und das Aussehen den geübten Beurteiler meistens nicht im Zweifel läbt. Verfasser besitzt ein geraspeltes, fermentiertes $\mathrm{Holz}$, welches im Jahre 1892 bei $8 \%$ Farbstoffgehalt $13 \%$ Wasser enthielt und nach 12 Jahren bei $8,4 \%$ Wasser keine Abnahme des Farbstoffgehaltes zeigte. Ebenso wurde ein fermentiertes Holz untersucht, welches $34,5 \%$ Wasser und $4 \%$ Farbstoffe (also für ein Holz mit $13 \%$ Wasser $5,2 \%$ Farbstoffe) euthielt und wegen seines Aussehens und Verhaltens beim Färben als gutes, unversehrtes $\mathrm{Holz}$ bezeichnet werden mußte, während Hölzer mit nur $8-11 \%$ Wassergehalt und $1,5-2,5 \%$ Farbstoff beim Probefärben sehr trübe Färbungen lieferten und auch schon wegen ihres Aussehens als schlecht bezeichnet werden konnten.

Über die Farbstoffe des Rotholzes und seiner Extrakte liegen wenig Untersuchungen vor, welche sich in der Verwendung mit der Färberei beschäftigen, sie beschränken sich fast alle mit der Ermittlung ihrer Konstitution, Darstellung von Derivaten, Oxydationsund Reduktionsprodukten u. s. w. Infolge 
dessen kennt man auch noch nicht genau die Rolle, welche die Farbstoffe dieses Holzes beim Färben spielen. Man hält das Brasileïn für den eigentlichen Farbstoff, nimmt jedoch bei der Verwendung des Materials hierauf nicht die Rücksicht wie bei Blauholz. Wahrscheinlich enthält das frisch geschlagene $\mathrm{Holz}$ in ähnlicher Weise wie Blauholz, ein Glukosid des Brasilins; diese Verbindung kann durch verdünnte Säuren oder Gärung in eine Zuckerart und Brasilin zerlegt werden, welches durch Oxydation in Brasileïn übergeht. Diese Prozesse gehen während des Konzentrierens der Extrakte vor sich, man sucht sie jedoch nicht durch Fermentation zu unterstützen. Infolge dessen enthalten die Rotholzextrakte nur wenig Brasileïn und hauptsächlich Brasilin, und man braucht beim Färben eine weit größere Menge von Farbmaterial, als bei Blauholz. Ein Färbeversuch gibt hierüber sehr schnell Aufschluß. Wolle, welche mit nichtoxydierenden Beizen $(5 \%$ Alaun und $5 \%$ Weinstein oder $3 \%$ Chromfluorid und $3 \%$ Weinstein) behandelt worden ist, färbt sich mit $0,5 \%$ reinem Brasilin nur schwach rot, resp. granatrot; sobald man jedoch das Farbbad vor dem Färben mit Ammoniak schwach alkalisch gemacht und alsdann $1 / 4$ Stunde lang mit Luft behandelt hat, so entstehen bedeutend dunklere Färbungen. Dasselbe ist der Fall, wenn man dem Farbbad kleine Mengen von essigsaurem Calcium $(1-2 \%)$ hinzufügt, oder. wenn man die Wolle mit einer oxydierenden Beize $(1 \%$ dichromsaures Kalium und $0,3 \%$ Schwefelsäure) vor dem Färben gebeizt hat. Infolge dessen wird man bei der Wertbestimmung durch Probefärben bei der Verwendung von Wolle, welche mit Alaun oder Chromfluorid und Weinstein gebeizt worden ist, und ron Garanzinstreifen, welche mit Tonerde und Chromoxyd bedruckt sind, um so höhere Resultate finden, je länger der Färbprozeß gedauert hat, und nur dann den gesamten Gehalt an Brasilin finden, wenn man Wolle verwendet, welche Chromsäure als Beize enthält.

Die Wertbestimmung durch Probefärben wird, wie bei Blauholz beschrieben worden ist, ausgeüfhrt. Die Vergleichsskala wird mit 10 Mustern hergestellt, welche mit von $0,05 \%-0,5 \%$ reinem Brasilin auf mit $1 \%$ chromsaurem Kalium und $0,5 \%$ Schwefelsäure gebeizter Wolle gefärbt worden sind. Brasilin kommt in fast reinem Zustand in den Handel und kann durch Umkristallisieren unter Zusatz von etwas schwefliger Säure leicht gereinigt werden. Bei festen Extrakten verwendet man für eine helle Färbung $0,5 \%$ und für eine dunkle $1 \%$, bei flüssigen
Extrakten $1 \%$ und $2 \%$, bei $\mathrm{Holz} 2,5 \%$ und $5 \%$.

Über die Untersuchung der Extrakte auf Zusatz anderer Stoffe, über den Aschengehalt normaler Extrakte u. s. w. liegen keine Angaben vor. Über den Wassergehalt des geraspelten Holzes wird wohl dasselbe wie bei Blauholz gelten; denn eine Probe enthielt nach 12 Jahren $8,3 \%$ Wasser, und ihr Farbstoffgehalt hatte sich nicht verringert.

Wegen der geringen Echtheit der mit Rotholz erzeugten Farblacke und des verhältuismäßig hohen Preises des Holzes und der Extrakte werden diese nur noch sehr wenig verwendet und dienen nur noch zum Nuancieren der mit anderen Farbstoffen erzeugten Farben und zusammen mit Gelbholz oder Flavin und Blauholz zur Herstellung von sogen. Holzbraun auf Wolle.

$\mathrm{Da}$ man sich über die Rolle, welche die Rotholzfarbstoffe beim Färben spielen, stets eine falsche Vorstellung gemacht hat, geht sshon aus den üblichen Färbrezepten hervor, welche so große Mengen von Farbmaterial vorschreiben, daß man das Rotholz überhaupt nicht als ein Farbholz ansehen könnte. Auch die chemische Natur der verwendeten Beizen nahmen keine Rücksicht darauf, ob Brasilin oder Brasileïn der färbende Stoff ist. Baumwolle beizte man z. B. mit $20-30 \%$ Sumach und nichtoxydierenden Tonerdesalzen oder Zinnverbindungen, bej denen auf die Anwesenheit ron reduzierendem Zinnchlorür keine Rücksicht genommen wurden, zum Färben wurde alsdamn $100 \%$, für falsches Türkischrot $200 \%$ Farbholz verwendet, und das Farbbad wurde nur lauwarm gehalten. Wolle wurde ebenfalls mit Tonerdesalzen gebeizt und mit etwa $50 \%$ Farbholz gefärbt; die Temperatur wurde jedoch nicht zum Kochen getrieben, sondern nur bis $80^{\circ}$, weil bei Kochtemperatur ein trübes Rot entstand, vormutlich weil Üheroxydationsprodukte entstehen, welche bei Rot sichtbarer sind als bei dem Hämateïnchromoxydfarblack. Nur bei den Farbrezepten für die Erzeugung von Granatrot, Puce auf Wolle findet man keine Angaben über die Menge des Farbholzes. Diese übersteigen das gewöhnliche $\mathrm{Ma} B$ nicht, weil hierzn die Wolle mit chromsaurem Kalium mit und ohne Zusatz von Schwefelsäure gebeizt wurde, so dah durch die Chromsäure in der Wolle eine Oxydation des Brasilins zu Brasileïn möglich war. Ferner weisen Angaben über die Behandlung des Rotholzes und seiner Abkochungen vor dem Färben darauf hin, daß man wenigstens schüchterne Versuche der Fermentation und Oxydation gemacht hat. Man lieb z. B. die Rotholzabkochungen 
längere Zeit an einem kalten Ort stehen, um reinere und ergiebigere Färbungen zu erhalten. Von dem bekannten Färbereichemiker Leuchs ist die Beobachtung gemacht worden, daß die Qualität des Rotholzes verbessert wird, wenn man es längere Zeit in feuchtem Zustande liegen läßt. Der vorteilhafte EinfluB des von Dingler empfohlenen Zusatzes von abgerahmter Milch zu der kochenden Rotholzabkochung kann vielleicht dadurch erklärt werden, daß durch das Kaseïn fremde Stoffe, wie Harze usw. abgeschieden werden, und durch die Milchsäure die Spaltung des Glukosids begüstigt wird.

Da die verschiedenen Rothölzer wohl auch einen verschiedenen, jedoch einen dem Blauholz annähernd gleichen Farbstoffgehalt, 5-10\%, haben, und die Extrakte denselben Gehalt wie die Blauholzextrakte haben könnten, so wïrden die in den alten Färbereirezepten angegebenen enormen Farbmaterialmengen auf das bei Blauholz übliche Maß zurückgehen, sobald man die bei diesem Material gemachten Erfahrungen bei der Verwendung von Rotholz und seiner Extrakte benutzen würde. Hierzu ist jedoch keine Aussicht, da das Rotholz in kurzer Zeit aus den Färbereien verschwunden sein wird.

Ciber die Rolle, welche die Farbstoffe des Sandelholz, Gelbholz, Fisettholz, der Quercitronrinde, der Gelbbeeren in der Färberei spielen, können nur Vernutungen ausgesprochen werden, da wissenschaftliche Untersuchungen über ihre Anwendung auch in den letzten Jahren nicht erschienen sind, und ihre Verwendung immer mehr abnimmt, trotzdem die mit ihnen hergestellten Farblacke sehr billig sind und viele von ihnen, namentlich die Kreuzbeeren- und Gelbholzfarblacke die meisten künstlichen Farbstoffe an Echtheit und Schönheit der Nuancen übertreffen.

In dem Sandelholz ist das Santalin als färbender Stoff aufgefunden worden, wegen der geringen Löslichkeit dieses Farbstoffes ist es jedoch unwahrscheinlich, daß er bereits fertig gebildet oder in freiem Zustande in dem Safte des lebenden Baumes enthalten war. Die jungen Schößlinge von Pterocarpus santalinus sind im Inneren gelb, erst nachdem sie an der Luft oxydiert sind, zeigen sie eine rote Farbe und die Färbekraft des Holzes nimmt mit dem Alter zu. Außerdem sind in dem Sandelholz auch noch braungefärbte schwerlösliche Verbindụngen aufgefunden worden. Es ist daher nicht unwahrscheinlich, daß auch diese Farbstoffe als Glukosid, in dem Safte der Pflanze enthalten sind und erst durch deren Zerfall und darauffolgende Oxydation entstehen. Aus der Krappwurzel komnte man lange Zeit auch keine brauchbaren
Präparate wegen der geringen Löslichkeit der Farbstoffe herstellen; es gelang dieses erst kurz vor der künstlichen Darstellung der Alizarinfarbstoffe, als man (Rochleder, Pernod, Meissonier, Kopp) die frischen, unveränderten Krappwurzeln extrahierte und aus der Lösung die Abscheidung der Farbstoffe durch Spaltung der gelösten Glukoside bewirkte.

Sandelholzextrakte kommen im Handel nicht vor; man muß wie früher bei Krapp, das möglichst fein gemahlene Holz den Farbbädern direkt zusetzen. Das Santalin färbt ungebeizte Wolle schwach rotbraun und bildet auf den mit Tonerde-, Zinnoxyd-, Eisenoxydund Chromoxydsalzen gebeizten Fasern rote und braune Farblacke. Wolle wird vielfach zuerst mit dem Farbbad, hierauf mit der Lösung der Metallsalze und zuletzt wieder mit dem Farbbad behandelt. Die mit Sandelholz vorgefärbte Wollfaser zeigt so grobe Neigung, aus einer Indigküpe das Indigweiß aufzunehmen, daß man mit zwei Zügen etwa denselben Farbenton auf ihr erzielt, zu welchem auf nicht vorgefärbter Wolle die doppelte Anzahl der Züge nötig ist. Man verwendet das Holz noch in Verbindung mit anderen Farbstoffen zur Herstellung von Mischfarben, Braun, Bronze und Oliv.

Die Wertbestimmung des Sandelholzes kann nur durch eine Probefärbung ausgeführt werden. Gewöhnlich verwendet man Wolle, welche mit $1-2 \%$ dichromsaurem Kalium gebeizt worden ist, es ist jedoch richtiger, dem Beizbad Weinstein als Reduktionsmittel zuzusetzen oder iberhaupt mit $3 \%$ Chromfluorid und $3 \%$ Weinstein zu beizen, so daß die gebeizte Wolle nur Chromoxyd enthält, da das Santalin keine Oxydation im Farbbade bedarf, sondern dadurch in braune Farbstoffe übergeht. Man kann sehr deutlich die Zunahme der Unreinheit der Farben erkennen, wenn man die Wolle mit Chromfluorid und Weinstein, mit chromsaurem Kalium und Weinstein, mit chromsaurem Kalium allein und mit chromsaurem Kalium und Schwefelsäure beizt, und man verwendet für Probefärbungen am besten $2 \%$ Zinnsalz, weil hierdurch die Färbungen nicht durch die Farbe des Chromoxyds beeinfluBt werden. Man kocht das sehr fein gemahlene Holz zuerst 1! Stunde lang in dem Bade aus und färbt, ohne das Holz zu entfernen, die gebeizte Wolle etwa eine Stunde lang. Eine Vergleichsskala kann man sich durch Färben von 10 Wollmustern mit von $1-10 \%$ zunehmenden Mengen eines guten Holzes herstellen; von dem zu untersuchenden Holz färbt man eine helle Farbe mit $5 \%$ und eine dunkle mit $10 \%$. 
Das in der Quercitronrinde als färbender Stoff aufgefundene Quercitrin ist in dem Safte der Rinde ursprünglich als Glukosid, Quercitrin enthalten, welches sich bei fortschreitendem Alter der Rinde teilweise in Quercetin und Isodulcit spaltet. Außerdem enthält die Rinde nicht unbeträchtliche Mengen von gerbsäureartigen Stoffen, welche bei Verwendung der Rindenabkochung der Lebhaftigkeit der Farblacke schaden; deshalb entfernt man sie vor dem Färben, indem unan die Abkochung mit Leimwasser oder Alaunlösung versetzt, aufkocht und den entstandenen Schaum abschöpft (Austreiben der Flotte). Bei Anwendung von Rinde und Extrakt kommt nur die Menge von Quercitrin zur Wirkung, welche während des Färbeprozesses sich in Quercitin und Zucker spaltet. Deshalb werden bei der Wertbestimmung der Rinde durch Probefärben nur geringe Mengen von Farbstoff gefunden, und man braucht beim Färben eine sehr große Menge von Farbmaterial. Vorteilhafter ist die Verwendung von Extrakten, in welchen die Spaltung des Quercitrins während der Fabrikation in größerem Maße eingetreten ist. Außerdem kann während der Herstellung und durch langes Aufheben ein Verderben des Extraktes nicht eintreten, da Quercetin nur bei Anwesenheit von Alkalien in braune Verbindungen übergeht. Die reinsten und kräftigsten Farben liefert ein zuerst von Amerika in den Handel gebrachtes Präparat, "Flavin“. Diesem ähnlich sind die bereits 1855 von Leeshing ${ }^{12}$ ) hergestellten Präparate; sie wurden dargestellt, indem man die zerkleinerte Rinde mit Säure kochte und den Rückstand durch Auswaschen von der Säure befreite, oder indem man die Rinde mit Wasser oder Sodalösung auskochte, aus der klaren Lösung das Quercetin durch Kochen mit Säure abschied, abfiltrierte und auswusch.

Das Quercetin ist im Wasser sehr schwer löslich und bildet mit Tonerde und Zinnoxyd schöne gelbe und orangegelbe, mit Chromoxyd braungelbe, mit Eisenoxyd schwärzlichgelbe Farblacke. Es wird zum Färben von Wolle und Baumwolle jedoch weniger zur Herstellung selbständiger Farben, sondern zugleich mit anderen Farbstoffen zur Herstellung von Mischfarben, zum Nuancieren von Blauholzschwarz verwendet.

Der Wert der Rinde und Extrakte kann nur durch Probefärben ermittelt werden. Das Resultat ist jedoch unsicher, und die Färbungen können nur mit einer Vergleichsskala verglichen werden, welche mit mustergiltiger Rinde oder Extrakt hergestellt ist,

12) Dingl. Journ. 139, 131. weil die mit reinem Quercetin hergestellten Farben viel reiner und klarer sind und ein anders nuanciertes Gelb zeigen, als die mit Rinde oder. Extrakt bereiteten. Die Wolle wird mit $2 \%$ Zinnsalz und $2 \%$ Oxalsäure gebeizt. Für die Vergleichsskala werden 10 Färbungen mit $0,05 \%-0,5 \%$ reinem Quercetin, oder $1-10 \%$ Extrakt oder $5 \%$ bis $50 \%$ Rinde und für die Probefärbung eine helle Färbung mit $5 \%$ Extrakt und $25 \%$ Rinde und eine dunkle mit 10\% Extrakt und $50 \%$ Rinde hergestellt.

In dem Gelbholz ist als Farbstoff die Morinsäure in freiem Zustande und als Kalksalz aufgefunden worden. Sie bildet, ohne eine Oxydation vorher nötig zu haben, mit Metalloxyden Farblacke. Außerdem enthält es, wie die Quercitronrinde, gerbsäureartige Stoffe, von denen das Maklurin oder die Moringerbsäure hergestellt worden ist. Infolge der Anwesenheit dieser Gerbsäuren in dem Holz und den Extrakten zeigen die mit ihnen hergestellten Farblacke weniger reine und klare Farben, als die mit reinem Morin bereiteten, und es ist schwer, bei Probefärbungen den Farbstoffgehalt dieser Materialien nach einer mit reinem Morin hergestellten Vergleichsskala abzuschätzen. Der Morinzinnfarblack zeigt ein reines Kanariengelb mit grünlichem Schein, während die mit Holz und Extrakten hergestellten Zinnfarblacke nach rot und rotbraun nuanciert sind. Die Zinn- und Tonerdefarblacke werden reiner und klarer, wenn man, wie bei Querzitron, die Gerbsäure vor dem Färben durch Leimlösung aus der Farbflotte ausscheidet. Diese Gerbsäuren schaden bei der gewöhnlichen Verwendung des Gelbholzes zur Herstellung von Mischfarben, Braun und Olive auf Wolle, und Blauholzschwarz auf Wolle und Baumwolle nichts; bei der Herstellung von Blauholzschwarz auf Wolle findet überdies durch die in der Wolle befindliche Chromsäure eine teilweise Oxydation des Morins und der Gerbsäuren statt, und der Chromoxydfarblack wird braungelb. Dieses ist deutlich sichtbar, wenn man Wolle, welche nur Chromoxyd als Beize enthält, und Wolle, welche mit dichromsaurem Kalium gebeizt worden ist, mit demselben Holz oder Extrakt oder reinem Morin färbt.

Für die Probefärbung, welche für die Wertbestimmung allein mabgebend ist, kann man mit 10 Wollmustern, welche mit $2 \%$ Zinnsalz und $2 \%$ Oxalsäure gebeizt sind, Vergleichsskalen mit $0,05 \%-0,5 \%$ reinem Morin, 0,5\%-5\% festem Extrakt, $1 \%$ bis $10 \%$ fluissigem Extrakt, 2,5\%-25\% Holz herstellen und von den zu untersuchenden Materialien eine helle und eine dunklere 
Färbung mit 2,5\% resp. $5 \%$ festem Extrakt, $5 \%$ resp. $10 \%$ flüssigem Extrakt und 12,5\% resp. $25 \%$ Holz auf Wolle färben, welche ebenfalls mit $2 \%$ Zinnsalz und $2 \%$ Oxalsäure gebeizt worden ist.

Das in den Gelbbeeren enthaltene Xanthorhamnin ist ein Glukosid, da es beim Kochen mit verdünnter Säure in eine Zuckerart und Rhamnetin zerfällt, welches von Herzig als Monomethylquercetin erkannt worden ist. Das Rhamnetin bildet mit Zinnoxyd und Tonerde lebhafte gelbe Farblacke. Man verwendet hauptsächlich Extrakte der Beeren nur noch in der Baumwolldruckerei für Dampfgell, Orange, Olive, sowie zum Nuannieren anderer Dampffarben. Das Rhamcetin ist für den Baumwollendruck sehr geeignet, weil beim Mischen der Lösungen des Farbstoffes und eines Metallsalzes nicht sofort, sondern erst nach einiger Zeit und unter dem Einflusse der Faser oder durch Dämpfen die Farblackbildung eintritt, nachdem die Druckmasse die Faser vollständig durchdrungen hat. Eine derartige Druckfarbe, eine sogenannte Applikationsfarbe, stellt man her durch Mischen einer Kreuzbeerenabkochung und einer mit Traganthgummi verdickten Lösung von Alaun und Zinnsalz. Der gelbe Farblack bildet sich, wenn man die bedruckten Stoffe zwei bis drei Tage in einem feuchten, warmen Raume aufhängt oder dämpft. Hierbei findet die Spaltung des Xanthorhamnins statt, so $\mathrm{da} B$ das dadurch freiwerdende Rhamnetin zur Geltung kommt.

Diese langsame Bildung des Farblackes tritt auch bei der Karminsäure der Farbsubstanz der Cochenille ein, deren Verwendung in der Färberei und Druckerei so gut wie aufgehört hat. Man führte deshalb das Färben der Wolle mit Cochenille in sehr verschiedener Weise aus:

1. Man behandelte die Wolle in der gewöhnlichen Weise in der Lösung der Beize und färbte hierauf in der Cochenilleabkochung.

2. Man färbte die Wolle in einem Bad, welches das Metallsalz, meistens Zinnsalz, und den Farbstoff enthielt.

3. Die Wolle wurde mit einem Teil des Metallsalzes, welches verwendet werden sollte, gebeizt und dann in einem neuen Bade, welchem man den Rest der Beize zusetzte, gefärbt.

4. Die Wolle wurde in einem Beizbad, welchem ein Teil der zum Färben erforderlichen Cochenille zugesetzt war, behandelt und dann mit dem Rest der Cochenille fertig gefärbt.

5. Die Wolle wurde mit der Lösung des Metallsalzes behandelt und hierauf in dem- selben Bade nach Hinzufügung der Cochenilleabkochung gefärbt.

Alle übrigen natürlichen Farbstoffe kennt man in den Färbereien und Druckereien höchstens noch dem Namen nach. In vereinzelten Fällen verwendet man wohl noch:

Die Curcumawurzel. Das in ihr enthaltene Curcumin färbt Baumwolle, Wolle und Seide direkt, ohne Anwendung einer Beize, gelb. Zur Herstellung eines reinen Gelb, welches durch die schwächsten Alkalien und schon durch Seife gebräunt wird und sehr unbeständig gegen Luft und Licht ist, wird die Curcumawurzel nicht verwendet, dagegen wird sie zur Herstellung von Mischfarben, z. B. zugleich mit Safranin für Ponceaurot auf Baumwolle wegen ihrer Billigkeit und leichten Art der Anwendung zuweilen noch gebraucht.

Die zur Orseillefabrikation dienenden Flechten enthalten mehrere farblose Verbindungen, welche größtenteils den Charakter von Säuren und eine den Glukosiden ähnliche Konstitution besitzen; diese Flechtensäuren zersetzen sich durch Gärung und bei Einwirkung ron Alkalien und Säuren in Orcin und Kohlensäure oder in Orcin und solche Verbindungen, welche bei der weiteren Zersetzung zum Teil in Orcin und Kohlensäure zerfallen. Das Orcin spielt die Hauptrolle bei der Bildung der Flechtenfarbstoffe, denn es geht unter dem Einflusse von Luft und Ammoniak zunächst in den Farbstoff Orceïn über, welches durch länger dauernde Einwirkung der Luft andere Oxydationsstufen und ebenso wie das Hämateïn Überoxydationsprodukte bilden kann; diese sind zum Teil in Wasser unlöslich und färben also nicht oder bilden Mischfarben. Daher enthalten die unter den verschiedensten Namen in den Handel gebrachten Orseillepräparate je nach den zu ihrer Herstellung verwendeten Flechten und je nach der Art der Herstellung die unter dem Namen Orceïn zusammengefaßten Oxydationsproduckte des Orcins und verschiedene unveränderte Flechtensäuren. Die gewöhnliche Orseille oder Orseille in Teig enthält außerdem noch die holzigen Teile der Flechten und viele Mineralstoffe; bei der Darstellung von Orseilleextrakt, einfach, doppelt, konzentriert, oder des Orseillekarmins werden in ähnlicher Weise, wie früher bei der Herstellung der Krappextrakte, die sch wer löslichen Flechtensäuren in leicht lösliche Kalk- oder Ammoniumsalze verwandelt und diese von den Flechten durch Extraktion mit Wasser getrennt; die klare Lösung wird alsdann entweder direkt mit Ammoniak der Luft ausgesetzt, oder es werden aus ihr durch Salzsäure die Flechtensäuren wieder abgeschieden, 
welche schließlich in Ammoniak gelöst mit Luft behandelt werden.

Bei der Herstellung des französischen Purpurs wird die Einwirkung der Luft auf die Flechtensäuren bei höherer Temperatur vorgenommen; aus der Lösung wird dann der Farbstoff durch Schwefelsäure oder Chlorcalcium abgeschieden. Das im letzten Falle entstandene Orceïncalcium ist im Wasser unlöslich und muß vor dem Färben mit Oxalsäure oder Schwefelsäure zersetzt werden ; das dadurch abgeschiedene Orceïn wird durch Ammoniak von dem oxalsauren oder schwefelsauren Calcium getrennt.

Bezeichnungen für Orseillepräparate sind Persio, Cudbear, roter Indigo, Orchelline.

Die unter dem Namen Orceïn zusammengefaßten Oxydationsprodukte des Orcins färben Wolle und Seide ohne Beize vioiett. Die Orseillepräparate dienen hauptsächlich zur Herstellung von Mischfarben, Braun und Modefarben, auf Wolle und Seide.

Da Orceïn noch nicht in reinem Zustande dargestellt worden ist, sondern immer Überoxydationsprodukte enthält, so kann eine Vergleichsskala mit diesem Körper nicht hergestellt werden. Infolge der verschiedenen Konzentration der Orseillepräparate müssen auch die Mengen, welche zur Herstellung einer Vergleichsskala und zur Probefärbung angewendet werden dürfen, immer durch einen Vorversuch ermittelt werden. Die Orseillepräparate werden sehr oft durch $\mathrm{Zu}$ satz anderer Fabstoffe, namentlich Fuchsin, verfälscht, zu deren Feststellung zahlreiche Vorschriften existieren. Sehr zu empfehlen ist hierzu die Benutzung der Kapillaranalyse, welche von Goppelsröder ${ }^{13}$ ) beschrieben worden ist.

\section{Zur Anwendung von Chlorwasserstoff als Urmaß fiir Titrimetrie.}

Von G. Lunge.

(Eingeg. d. 2. 6. 1904 )

Auf S. 716 d. Z. erwähnt W. A. Roth, daB er einen ähnlichen Vorschlag wie Raschig (S. 577 schon auf dem vorjährigen Kongresse in Berlin vorgetragen habe. Beide Herren haben übersehen, daß genau dasselbe Verfahren, wie es von Raschig angegeben wird, schon 1898 ron Moody ausführlich beschrieben worden ist in J. Am. Chem. Soc. 73, $658 \mathrm{ff}$. Ein Auszug aus dessen Aufsatz mit Abbildung steht im Chem. Centralbl. 1898, II, 638, und ein kürzerer in der (noch nicht ausgegebenen) fünften Auflage der (Chemisch-technischen Untersuchungsmethoden ${ }^{*}$, I, S. 106. Der Name Moody ist dort durch einen

13) Romens Journal 1887, Ausgabe B. S. 1. Goppelsröder, Die Darstellung der Farbstoffe durch Elektrolyse S. 56. von mir übersehenen Satzfehler als, Mundy wiedergegeben. Hätte ich Raschigs Resultate damals schon gekannt, so würde ich das Verfahren ausführlicher berücksichtigt haben.

\section{Quantitative Phosphor= und Stick= stoffbestimmung in organischen Kör= pern mit Hilfe von Natriumperoxyd. ${ }^{1}$ )}

(Dritte Mitteilung über die Anwendung des $\mathrm{Na}_{2} \mathrm{O}_{2}$ in der organischen Analyse ${ }^{2}$ ). Mitteilung aus dem technolog. Laborat, der Chem. Reichsanst. und Zentral.Versuchs. station zu Budapest).

Von Dr. phil. Fritz vox Koxek, Universit.Dozent und Staatschemiker.

$$
\text { (Eingeg. d. 9./2. 1904.) }
$$

Organisch gebundener Phosphor läßst sich durch Verbrennung der betreffenden Substanz mit überschüssigem $\mathrm{Na}_{2} \mathrm{O}_{2}$ quantitativ zu Phosphorsäure oxydieren, welche im Entstehungsmomente durch das im Überschusse vorhandene $\mathrm{NaOH}$ als $\mathrm{Na}_{3} \mathrm{PO}_{4}$ fixiert wird. Unter den obwaltenden Umständen, hauptsächlich der hohen Reaktionstemperatur, ist auch die Bildung von Pyrophosphat in Erwägung zu ziehen, diese dürfte jedoch durch gleichzeitig, aus den? Wasserstoffe, entstandenes Wasser spontan in Orthophosphorsäure übergeführt werden. Auf diesen Befund, gleichgültig ob es sich hierbei um Ortho- oder Pyrosäure handelt, läßst sich nun ein höchst einfaches und rasch ausführbares quantitatives Verfahren der organisthen Phosphorbestimmung basieren. Folgende Arbeitsweise hat sich bewälurt: Die Verbrennung wird in den von mir auch bei der qualitativen organischen Analyse benutzten Stahl- oder Nickeltiegeln vorgenommen: auf $10-15 \mathrm{~g} \mathrm{Na}_{2} \mathrm{O}_{2}$ kann man bis $0.5 \mathrm{~g}$ organische Substanz nehmen, auch wenn diese bis $80 \%$ Kohlenstoff enthält; ist der Gehalt an letzterem zu gering, so wird er, um sichere Zündung zu erreichen, durch indifferente, also P-freien Substanzen ergänzt. Nachdem die zu analysierende Verbindung den Achatmörser verlassen, wird sie durch die feinste Müllergaze gebeutelt; diese Auflockerung der kleinsten Partikelchen sollte bei keiner quantitativen $\mathrm{Na}_{2} \mathrm{O}_{2}$-Analyse unterlassen werden, da sie die innige Berührung der organischen Teilchen mit dem Oxydationsmittel ganz wesentlich fördert; handelt es sich um schwerverbrennliche Substanzen, z. B. Alkaloide, Kohlen, so darf sie, wie aus meinen Erfahrungen hervorgeht, niemals unterbleiben, da es sonst nicht möglich ist, eine quantitative Oxydation zu erzielen. Das so vorbereitete Analysenobjekt wird mit Hilfe eines Drahtes in das $\mathrm{Na}_{2} \mathrm{O}_{2}$ eingerührt, der Draht mit etwas Peroxyd abgespült und die Zündung, nachdem der Tiegel in eine Schale mit kaltem Wasser gestellt wurde, in gewohnter Weise vorgenommen. Darauf entferut man den Sclnraubendeckel, spült ihn in ein Becherglas, stellt den Tiegel hinein und läßt nun, nachdem ein gut schlieken-

1) Der Akademie der Wissenschaften, Budapest, vorgelegt in der Februarsitzung. 